CATALYTIC DECOMPOSITION OF CARBON MONOXIDE

ON SINGLE CRYSTALLINE RUTHENIUM

\author{
A THESIS \\ Presented to \\ The Faculty of the Division of Graduate Studies \\ by \\ Kamal Jeet Singh
}

In Partial Fulfillment

of the Requirements for the Degree

Master of Science in Metallurgy

Georgia Institute of Technology

Apri1, 1976 


\section{CATALYTIC DECOMPOSITION OF CARBON MONOXIDE \\ ON SINGLE CRYSTALLINE RUTHENIUM}

Approved :

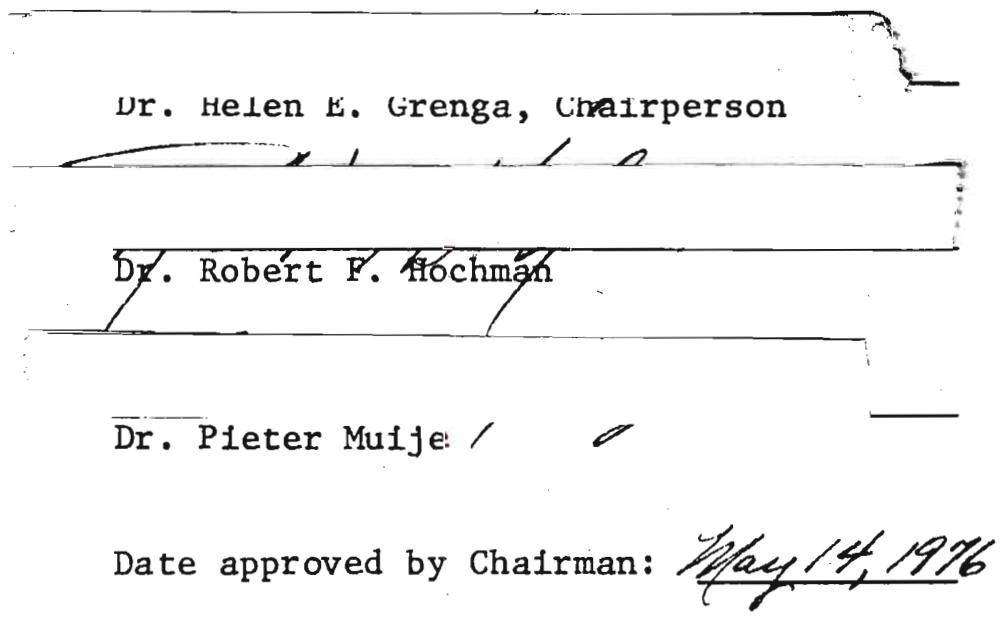




\section{ACKNOWLEDGMENTS}

The author expresses his gratitude to his thesis advisor, Dr. Helen E. Grenga, for her guidance and encouragement. He is also grateful to Dr. Robert F. Hochman and Dr. Pieter Muije for having taken time to review this work as members of the reading committee.

The author is also grateful to faculty members, staff and the graduate students in the metallurgy program for their ever-helpful attitude. Special thanks are, however, due to Mrs. Frances Smith who helped in the design of the apparatus, and Mr. Donald E. Lillie of the Chemistry department for making the apparatus and the occasional changes so prompt1y done. To Mr. James Johnson and his colleagues in the Engineering Experiment Station, gratitude is extended for their invaluable help in providing the RHEED and SEM facility.

Gratitude is also expressed to the National Sclence Foundation for providing the financial support for this work; and the School of Chemical Engineering of Georgia Tech where the work was carried out. Appreciation is due for my wife, Surjeet, who bore with me with patience during this period and always showed fortitude and calm in hardest of times; and my son Yashpaul (7) and daughter Anju (9), who showed unusual understanding for their age. My father, Jaswant Singh, who ventured in the early $30^{\prime}$ 's to enter the then scarcely known but exciting field of metallurgy, and my mother, Saraswaty, get my greatest admiration for consistent encouragement. 
TABLE OF CONTENTS

Page

ACKNOWLEDGMENTS . . . . . . . . . . . . . . . . . . . ii

LIST OF TABLES . . . . . . . . . . . . . . . . . . iv

LIST OF ILLUSTRATIONS . . . . . . . . . . . . . . . . v

SUMMARY . . . . . . . . . . . . . . . . . . . . vi

Chapter

I. INTRODUCTION . . . . . . . . . . . . . . . 1

II. BACKGROUND . . . . . . . . . . . . . . . . 2

A. Decompostition of $\mathrm{CO}$ on $\mathrm{Ni}$

1. Single Crystal Sphere

2. Single Crystal Thin Films

B. Decomposition of $\mathrm{CO}$ on Other Metals

III. EXPERIMENTAL TECHNIQUES . . . . . . . . . . . . . 7
A. Materials
B. Vacuum System
C. Specimen Preparation
D. Annealing and Reaction
E. Specimen Examination
1. For Crystal Orientation
2. After the Reaction

IV. RESULTS AND DISCUSSION . . . . . . . . . . . 15
A. Results
B. Discussion
1. Effect of Crystal Orientation on Activity
2. Active Sites for CO Decomposition

V. CONCLUSIONS AND RECOMMENDATIONS . . . . . . . . . . . 27

A. Conclusions

B. Recommendations

BIBLIOGRAPHY . . . . . . . . . . . . . . . . . 29 


\section{LIST OF TABLES}

Table

Page

1. Summary of Experimental Conditions . . . . . . . . . 16

2. Result of RHEED on Specimen from Reactions IV and VI . . 18 
1. Schematic of the Vacuum System . . . . . . . . 8

2. Tool for Spark Erosion Machining . . . . . . . . . 11

3. Ruthenium Single Crystal After Spark Erosion Machining ................... 11

4. Pattern of Graphite Deposition on Ruthenium Single Crystal After Treatment with $\mathrm{CO}$ at $550^{\circ} \mathrm{C}$. . . . . . 17

5. Schematic Representation of Graphite Deposition on a Section of Stereographic Projection on Ru . . . . . . 19

6. Graphite Deposition on Low Index Regions . . . . . . . 22

7. Graphite Deposition on High Index Regions . . . . . . 23 
SUMMARY

The purpose of this research was to study the interaction of carbon monoxide with single crystalline ruthenium. It was anticipated and confirmed by these experiments that ruthenium catalyses the decomposition of carbon monoxide in the temperature range of 500 to $550^{\circ} \mathrm{C}$. An important part of this research was to determine any crystallographic specificity for the decomposition reaction and to correlate these results, if possible, with those on nickel in order to identify active sites for the decomposition.

In many heterogeneous catalytic reactions it is known that the catalytic activity varies with crystal orientation of the catalyst and that relatively few sites on the catalyst surface participate in the reaction. For the catalytic decomposition of carbon monoxide on nickel, it has been shown that these sites are certain steps on one of the low index regions. Carbon monoxide also decomposes on iron, but the formation of carbides prior to that of graphite hinders the identification of active surface sites for the inftial decomposition.

A ruthenium single crystal, cut to a spherical shape, was used in this research in order to expose all posstble crystal orientations to the carbon monoxide environment. After electropolishing to produce a smooth, strain-free surface, the specimen was annealed in hydrogen, outgassed in vacuum and then treated with carbon monoxide at 500 to $550^{\circ} \mathrm{C}$ for times varying from 1 to 96 hours.

The effect of crystal orientation on the reaction was apparent 
from the resulting pattern of deposition on the ruthenium crystal. The specimen was examined by several techniques, the most successful of which were optical microscopy and reflection high energy electron diffraction (RHEED). RHEED results revealed only graphite on the ruthenium surface; the graphite morphology was then studied with optical microscopy.

Optical microscopy revealed graphite streamers centered about $\langle 0001\rangle,\langle 10 \overline{10}\rangle$, and $\langle 10 \overline{1} 1\rangle$ poles. The deposition began on these low index regions and spread outwards from them. These results are comparable to those on nickel and can also be explained by decomposition of carbon monoxide at steps on these low index regions. A significant difference for ruthenium, however, is the high activity for decomposition on three low index regions, compared to only one for nickel. 
CHAPTER I

\section{INTRODUCTION}

Carbon monoxide is known to decompose catalytically on the surface of iron, cobalt, and nickel at about $550^{\circ} \mathrm{C}(1,2)$. The decomposition reaction is given by the following equation:

$$
2 \mathrm{CO}=\mathrm{CO}_{2}+\mathrm{C}
$$

After the reaction carbon is found on the surface or in the metal in the form of solid solution, carbides and/or graphite depending on the metal catalyst. Ruthenium behaves similarly to iron, cobalt, and nickel in many catalytic reactions involving carbon monoxide, and it is expected to behave similarly in the carbon monoxide decomposition reaction.

The purpose of this research is to confirm this expectation and to study any topographical and crystallographic influences of the ruthenium surface on the catalytic reaction. Thus the first experiments were directed mainly towards establishing the conditions for the reaction and identifying the solid state products of the interaction of carbon monoxide with ruthenium. The decomposition products of the reaction are examined by one or more of several techniques including optical microscopy, transmission electron microscopy and diffraction, RHEED, and SEM. From these results the relative activity of various crysta11ographic regions is determined. An attempt is also made to correlate the graphite deposition behavior on ruthenium with the proposed theory of active sites for this reaction. 
CHAPTER II

BACKGROUND

A heterogeneous catalytic reaction involving gas and solid phases takes place on the surface of the solid catalyst. However, relatively few surface sites actually participate in the reaction. The catalytic activity of metal surfaces has been shown to be a function of the crystal orientation exposed to the reactants (3). For a basic understanding of the behavior of metals in heterogeneous catalysis, it is important to know the activity of various crystallographic orientations, as well as the nature of sites where the catalytic reaction takes place on these orfentations.

The catalytic decomposition of carbon monoxide on monocrystalline nickel, which produces graphite surface deposits, has been used to study the active sites for this catalytic reaction $(4,5)$. Ruthenium behaves similarly to iron, cobalt, and nickel in many catalytic reactions involving carbon monoxide. However, the decomposition of carbon monoxide on ruthentum has not been previously reported, and the background for the present study was primarily derived from previous studies of this reaction on other metals.

A ruthenium carbide of unknown composition has reportedly (6) been formed at about $2500^{\circ} \mathrm{C}$, but there is no report of a carbide of ruthenium existing in the temperature range of 500 to $550^{\circ} \mathrm{C}$. Molten ruthentum reportedly (6) dissolves up to 4.8 weight $\%$ of carbon, which separates to form graphite upon cooling. Therefore, it is expected that if carbon 
monoxide decomposes on ruthenium, graphite will be deposited on the surface at the reaction sites. This expected behavior of ruthenium would be similar to that shown by the most active regions of nickel. Also, since the results of catalytic decomposition of carbon monoxide on nicke1 are more extensive in terms of identification of active orientations and active sites, a review of the results on nickel is given separately from other iron group metals.

\section{A. Decomposition of $\mathrm{CO}$ on $\mathrm{Ni}$}

\section{Single Crystal Sphere}

The evolution of the large single crystal sphere method for the study of catalytic reactions on the surface of metals has been described by Gwathmey and Cunningham $(7,8)$ and Gwathmey (9).

The catalytic decomposition of carbon monoxide to deposit graphite on the surface of nickel at high temperature was used by Leidheiser and Gwathmey (3) to determine the effect of crystallographic orientation on this heterogeneous catalytic reaction. At $550^{\circ} \mathrm{C}$ they observed that graphite formed quickly at (111) faces and then spread out from there. Even after prolonged reactions small square regions around $\langle 100\rangle$ poles remained free from graphite. Kehrer and Leidheiser (10) also performed a large number of carbon monoxide reactions on single crystal spheres of inickel. They stated that, "Careful examination during the course of the reaction indicated that the regions surrounding the $\{111\}$ faces were slightly more active than the $\{111\}$ faces themselves. These regions are associated with the minor crystal faces of high index surrounding the (111) face." They reported that the relative rate of activity was in 
the following decreasing order: high index faces about <111> poles, \{111\} faces; $\{110\}$ and $\{100\}$ faces. There was no effect of pretreatment on the high activity of $\{111\}$ regions compared to $\{110\}$ and $\{100\}$ regions, even when the latter had rougher surfaces. In fact some pretreatments (for example, electrolytic etching with $\mathrm{H}_{2} \mathrm{SO}_{4}$ ) rendered $\{110\}$ and $\{100\}$ inactive but the $\{111\}$ st111 remained active. Cox, et a1. (11), using transmission electron microscopy of extraction replicas, studies the morphology of graphite deposits formed on spherical single crystals of nickel and some nickel-copper alloys. They observed that graphite formed as streamers with their heads pointing towards the center of the nearest active region. They concluded that the carbon nucleates at the active sites and then extends away from them. They suggested that the active sites may be dislocations, atomic steps and/or kink sites.

\section{Single Crystal Thin Films}

Although the single crystal sphere method is very useful to determine the effect of crystallographic orientation on catalytic activity, it cannot be used to determine whether dislocations, steps or other features are also the active sites on a given surface.

Oriented thin films of nickel were used by Grenga $(4,5)$ to determine the nature of active sites for the catalytic decomposition of carbon monoxide. Thin films of (111), (110), and (100) orientations were reacted with carbon monoxide at $550^{\circ} \mathrm{C}$ and atmospheric pressure for times varying from a few minutes to several hours. Some of the reactions were also carried out at lower carbon monoxide pressures of $10^{-3}$ and 300 torr. Transmission electron microscopy and diffraction were used to observe 
the nickel thin films and shadowed extraction replicas of the surface, both before and after reaction. The results of this work showed that certain steps on (111) oriented films were the most active sites for the catalytic decomposition of carbon monoxide. It was suggested that kinked steps might be more active than those without kinks and that polyatomic steps might be more active than monoatomic steps. She conclusively showed that dislocations and other lattice imperfections were not the most active sites for this catalytic reaction.

\section{B. Decomposition of $\mathrm{CO}$ on Other Metals}

In addition to nickel, several other metals catalytically decompose carbon monoxide. Kehrer and Leidheiser (10) studied the reaction with several metals. They established that $\mathrm{Cu}, \mathrm{Ag}, \mathrm{Rh}$ and $\mathrm{Pd}$ were completely inactive. Chromium and molybdenum may have been slightly active, but the results were rather inconclusive. Cobalt in both hexagonal and f.c.c. forms, nickel and iron, however, were active for the catalytic decomposition of carbon monoxide. The most pertinent results of this and other studies are briefly given below.

Iron: The decreasing order of activity at 450 and $550^{\circ} \mathrm{C}$ was found by Kehrer and Leidheiser (10) to be as follows: minor faces with unequal indices; minor faces of type (211), (311), (411) etc.; minor faces of type (221), (331), (441) etc.; minor faces of type (210), (310), (410) etc.; (111) and (110); (100). Iron differed from other metals of the group in that it first formed carbides, such as $\mathrm{Fe}_{3} \mathrm{C}$, before graphite formed. From the reactions at $350^{\circ} \mathrm{C}$ they also found evidence of compounds like $\mathrm{Fe}_{20} \mathrm{C}_{9}$ and $\mathrm{Fe}_{3} \mathrm{C}_{4}$. 
Ratliff (12) reacted (100) single crystal thin film of iron with carbon monoxide. He reported that the carbon from catalytic decomposition of carbon monoxide went into the matrix of iron. The first detectable solid phase product of the reaction was found to be cementite decorating the dislocations and dislocation sub-boundaries within the iron matrix. Graphite nucleated only when cementite began to dissociate (at a temperature as low as $450^{\circ} \mathrm{C}$ ). The graphite flakes were located at relatively large surface steps and holes in the iron film such that the (002) graphite planes tended to lie parallel to (110) and (200) iron planes. Magnetite $\left(\mathrm{Fe}_{3} \mathrm{O}_{4}\right)$ was discounted since it was not found as a product of CO attack.

Cobalt: In both the h.c.p. and f.c.c. forms, cobalt catalysed the decomposition of carbon monoxide (10). The hexagonal phase, which is stable at temperatures below $420^{\circ} \mathrm{C}$ was less active than the f.c.c. phase. However, the difference in temperature may account for the difference in activity. The decreasing order of activity of f.c.c. cobalt between 450 and $600^{\circ} \mathrm{C}$ was found to be: minor faces with unequal indices; $\{211\},\{311\},\{411\} ;\{111\} ;\{110\}$; and $\{100\}$, while that for h.c.p. cobalt at $410^{\circ} \mathrm{C}$ was: $\{0113\} ;\{1124\} ;\{0110\} ;\{0111\} ;\{0001\}$. 
CHAPTER III

\section{EXPERIMENTAL TECHNIQUES}

\section{A. Materials}

A ruthenium single crystal rod was procured from Materials Research Corporation. The crystal was $1 / 4$ inch $(6.35 \mathrm{~mm})$ diameter and 2 inch $(50 \mathrm{~mm})$ in length.

Research grade carbon monoxide and hydrogen were obtained from Matheson, Inc.; the hydrogen was $99.9995 \%$ pure and the composition of the carbon monoxide was reported from their analysis to be as follows:

$$
\begin{aligned}
& \mathrm{CO}_{2}=5 \mathrm{ppm} \\
& \mathrm{O}_{2}=5 \mathrm{pmm} \\
& \mathrm{H}_{2}=100 \mathrm{pmm} \\
& \mathrm{N}_{2}=800 \mathrm{pmm} \\
& \mathrm{Ar}=10 \mathrm{pmm} \\
& \mathrm{CO}=\text { Balance. }
\end{aligned}
$$

\section{B. Vacuum System}

The vacuum system used for the reaction is shown schematically in Figure 1.

The system was a conventional high vacuum system, equipped with a mechanical pump, oil diffusion pump, liquid nitrogen trap, pirani gauge and Veeco ionfzation gauge. The system was capable of a vacuum in the $10^{-7}$ torr range, but was typically used in the low $10^{-6}$ torr range. A diaphragm gauge was also present in the roughing line, and 


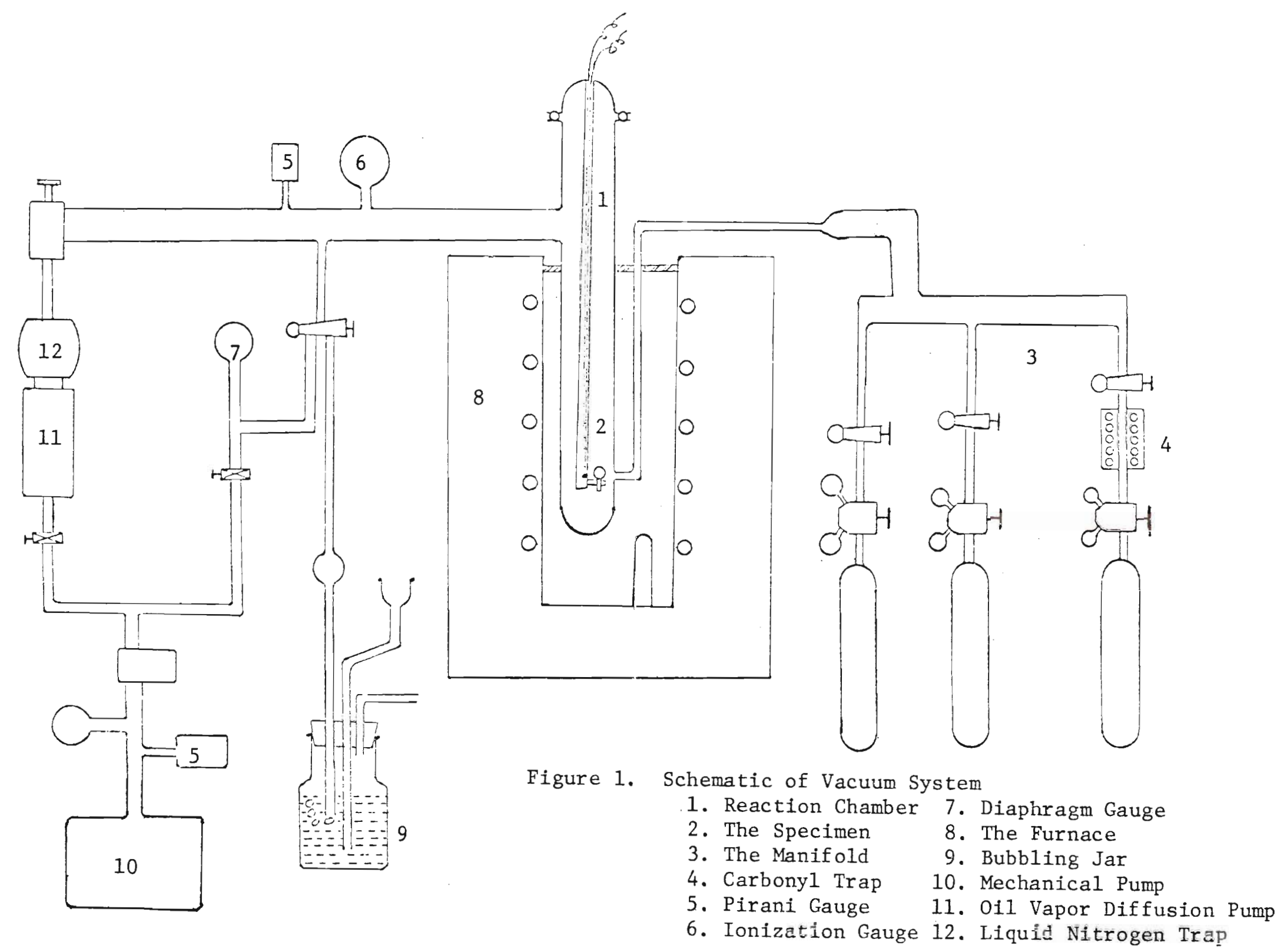


with the pumps valved off, could be used to determine when the system reached atmospheric pressure. During the reaction gases were flowed through a water trap to the outside atmosphere. This water trap also provided an indication of the gas flow rate.

Most of the system was constructed of pyrex glass tubing; viton ' $O$ ' ring seals with apiezon ' $T$ ' high vacuum lubricant were used throughout. The glass was wrapped with heating tape for bake out purposes. The reaction chamber consisted of two parts, a fixed part which was made of quartz tubing about 1 1/2 inch diameter and 15 inch long, and a removable part (specimen holder) also made of quartz tübing and joined to the fixed part via a viton ' 0 ' ring seal. The specimen holder had a long piece of small diameter quartz tubing, on the end of which was a quartz ring to hold the specimen upright and in the direct path of the entering gases. A thermocouple was inserted in the atmosphere side of the long tubing of the specimen holder. This allowed temperature readings near the specimen. This assembly was positioned in a pit type Lindbergh furnace such that the specimen was in the middle of the hot zone. The temperature was controlled by the Lindbergh controller console through a platinel thermocouple near the bottom of the furnace chamber. The temperature set on the controller was usually about $5^{\circ} \mathrm{C}$ higher than the specimen temperature, as measured by the chromel-alumel thermocouple near the specimen.

The gas entrance to the reaction chamber was located near the bottom of the fixed part; a gas manifold and a system of valves and gauges for each line were incorporated in the system. The carbon monoxide gas line was provided with a hot trap; this trap decomposed nickel 
carbony 1 which was found present in the gas and had interfered with preliminary experiments. After assembly, the system was initially baked for more than 48 hours at $120^{\circ} \mathrm{C}$ with the reaction chamber at $300^{\circ} \mathrm{C}$; the pressure during bakeout was about $4 \times 10^{-6}$ torr. Subsequently dry nitrogen was leaked into the system whenever it was opened.

\section{Specimen Preparation}

The ruthenium single crystal was machined to a spherical shape by spark erosion technique on a servomet spark machine. A low spark energy was used for slower machining in order to minimize the depth of strained matrix. Spark machining was chosen in preference to mechanical machining due to high hardness, brittleness and mechanical anisotropy of ruthenium. The tool wear, however, was severe, as shown in Figure 2; it was necessary to use this specially designed tool of stainless steel which, during machining, brought new tool surface in contact with the ruthenium crystal (by the servomechanism of the machine). Approximately one inch of tool length was consumed to machine a depth of $1 / 16$ inch $(1.6 \mathrm{~mm})$ on the radius of the crystal. Due to the high degree of anisotropy of the ruthenium crystal, the erosion was non-uniform giving a pattern of rings centered around the $[0001]$ pole, as shown in Figure 3.

The specimen was thus machined to a spherical shape about $1 / 4$ inch in diameter, with a stem $1 / 8$ inch in diameter and $1 / 4$ inch long to facilitate handling of the crystal. The machined specimen was mechanfcally polished with successively finer grades of abrasive polishing paper and then with a felt colth, wet with an aqueous suspension of $0.3 \mu$ alumina. 


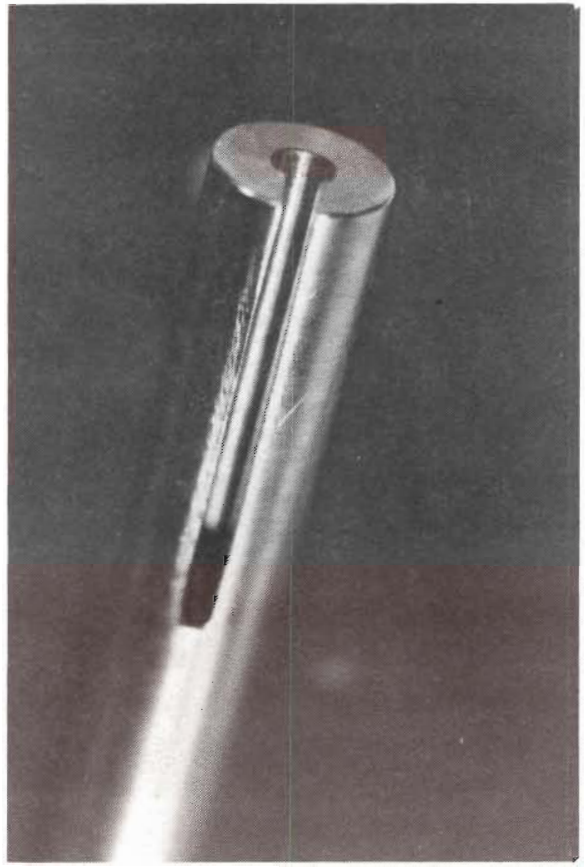

(a)

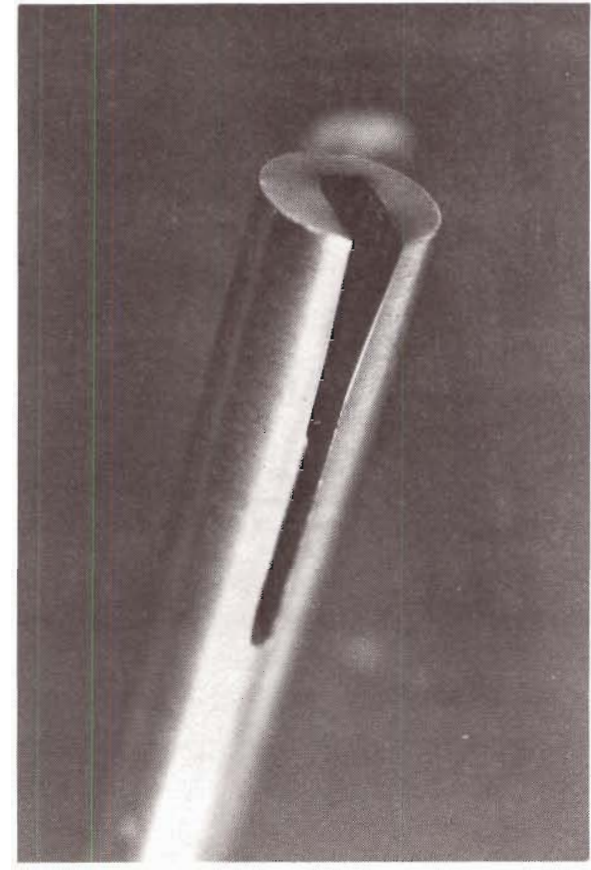

(b)

Figure 2. Tool for Spark Erosion Machining, X1

(a) Before Use, (b) After Use

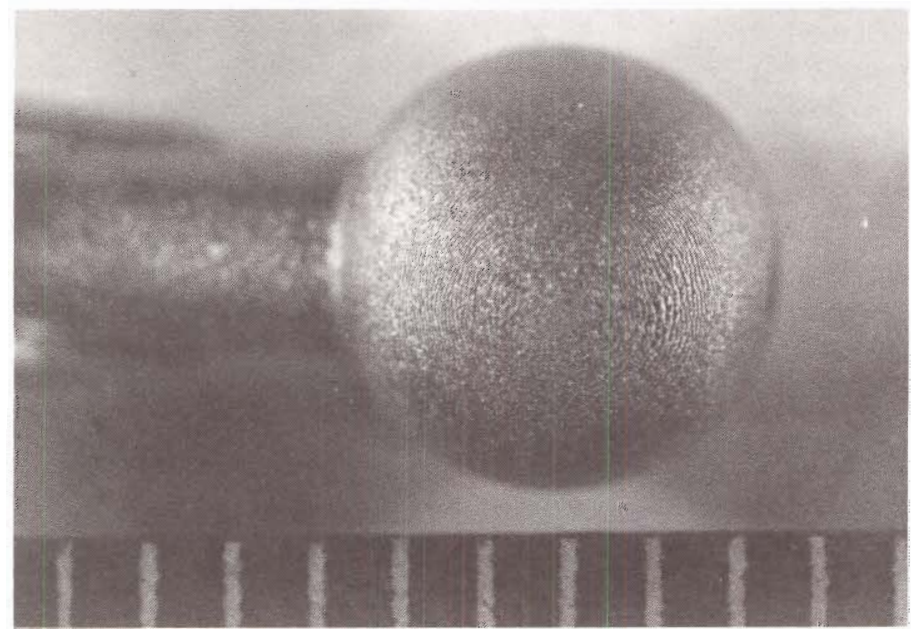

Figure 3. Ruthenium Single Crystal After Spark Erosion Machining (0001) is at center of concentric rings; scale at bottom has $\mathrm{mm}$ divisions 
Electropolishing was then used to obtain a smoother surface and to eliminate the strained surface layers resulting from mechanical abrasion. The electrolytes specified in the literature $(13,14)$ for electropolishing ruthenium are molten salts. However, an aqueous electrolyte was desired, and was developed based on the electropolishing theories $(13,14)$ as well as on reported etching solution for F.I.M. wire specimens $(17,18)$. This solution is as follows: $5 \mathrm{~g}$ potassium hydroxide, $6 \mathrm{~m} 1$ glycerine, $80 \mathrm{ml}$ water, and up to $3 \mathrm{ml}$ of used electrolyte. The electrolyte was aged for 24 hours and then used with the following electropolishing conditions:

$$
\begin{array}{ll}
\text { Temperature } & =-3 \text { to } 0{ }^{\circ} \mathrm{C} \\
\text { Voltage } & =8 \text { to } 9 \mathrm{~V} . \mathrm{d} . \mathrm{c} . \\
\text { Time } & =5 \text { to } 10 \text { minutes. }
\end{array}
$$

Brisk stirring of electrolyte was essential. The voltage was rather critical and depended on minor variations in the distance between the electrodes and the temperature. Slight variations in voltage resulted in faceting or etching of high index areas surrounding the $\{0001\}$ planes. After electropolishing, the spectmen was rinsed thoroughly in distilled water, dried in a stream of dry nitrogen and placed in the reaction chamber which was then evacuated immediately.

\section{Annealing and Reaction}

After the system had been evacuated to approximately $10^{-6}$ torr, the furance was turned on and set at the reaction temperature. The specimen was annealed in vacuum or in hydrogen. When hydrogen annealing 
was used, an initial flushing procedure was followed. Hydrogen was admitted to the system to a pressure of 200 to 500 micron and then evacuated to $10^{-5}$ torr or less. This procedure was repeated four or five times before hydrogen was finally introduced to 760 torr. After annealing the specimen for one hour in hydrogen, the apparatus was evacuated and the specimen was annealed for one hour in vacuum at the reaction temperature.

Carbon monoxide was then admitted slowly to a pressure of 760 torr, and the gas exit stopcock was opened to allow carbon monoxide to flow through the water trap and outside. The rate of gas flow was adjusted by this stopcock, leaving other valves in the gas line completely open. This procedure actually minimized the risk of the water vapor backing into the reaction chamber. Care was also taken, however, to minimize the positive pressure in the system.

After reacting the specimen with carbon monoxide for a specified time, the gas entrance and exit valves were closed, and the system was evacuated to below $10^{-5}$ torr; the furnace was then turned of $f$ and the crystal allowed to cool to room temperature before removal.

\section{E. Specimen Examination}

\section{For Crysta1 Orientation}

A back reflection Laue pattern was initially used to determine the orientation of the crystal (later it was found that the anisotropy of the catalytic reaction also clearly revealed the orientation). The orientation was also revealed by anisotropic etching during the specimen preparation procedures. The spark machining revealed the <0001> poles 
as shown in Figure 3. Furthermore, after electropolishing faceting frequently occurred on several planes giving a pattern again related to the orientation. These facets were minimized for subsequent reactions by careful control of the electropolishing parameters. 2. After the Reaction

Al1 specimens were examined by optical microscopy on a Vickers metallograph; the photographs were taken by a polaroid land camera. Scanning electron microscopy and reflection high energy electron diffraction were used for some specimens to observe and identify surface deposits after the reaction. Platinum shadowed extraction replicas of one of the specimens were examined with transmission electron microscopy and diffraction. The etching solution used to remove the extraction replicas was $5 \% \mathrm{KOH}$ in distilled water. 
CHAPTER IV

\section{RESULTS AND DISCUSSION}

\section{A. Results}

Table 1 gives a summary of experimental conditions for the annealing and carbon monoxide treatment of ruthenium. In experiments I and II vacuum annealing alone was used prior to carbon monoxide treatment. The results of high energy electron diffraction (RHEED) showed the presence of only ruthenium oxide, even after a six hour exposure to carbon monoxide.

In experiments III through VII, the ruthenium crystal was annealed in hydrogen for one hour prior to carbon monoxide treatment. The RHEED results for two of these experiments, which are given in Table II, confirm the presence of graphite. Since the graphite deposition was fairly heavy and the underlying ruthenium orientation could not be determined exactly, any epitaxial relation between graphite and ruthenium could not be obtained from these results.

After a six hour treatment with carbon monoxide (experiments III and IV), only a small amount of deposition located around the <0001> pole, was observed by optical microscopy.

After reaction for twelve or more hours graphite deposits were found on a larger area of the ruthenium surface. The amount of graphite deposition increased with increase in carbon monoxide exposure time, and the boundaries of the graphite deposits became increasingly well defined revealing the ruthenium hexagonal symetry, as shown in Figure 4. The 
Table 1. Summary of Experimental Conditions

\begin{tabular}{|c|c|c|c|c|c|c|}
\hline \multirow[b]{2}{*}{$\begin{array}{l}\text { Experiment } \\
\text { Number }\end{array}$} & \multicolumn{3}{|c|}{ Annealing } & \multicolumn{3}{|c|}{ Reaction With CO } \\
\hline & $\begin{array}{c}\text { Temperature } \\
\left({ }^{\circ} \mathrm{C}\right)\end{array}$ & $\begin{array}{c}\text { Time } \\
\text { (Minutes) }\end{array}$ & $\begin{array}{c}\text { Pressure } \\
\text { (Torr) }\end{array}$ & $\begin{array}{l}\text { Temperature } \\
\left({ }^{\circ} \mathrm{C}\right)\end{array}$ & $\begin{array}{l}\text { Flow Rate } \\
\text { (m1/min) }\end{array}$ & $\begin{array}{l}\text { Time } \\
\text { (Hours) }\end{array}$ \\
\hline I & 500 & 210 & $3 \times 10^{-6}(a)$ & 500 & - & 1 \\
\hline II & 500 & 210 & $2 \times 10^{-6}(a)$ & 500 & - & 6 \\
\hline \multirow[t]{2}{*}{ III } & 500 & 60 & $760(b)$ & & & \\
\hline & 500 & 60 & $2 \times 10^{-6}(a)$ & 550 & $40-50$ & 6 \\
\hline \multirow[t]{2}{*}{ IV } & 480 & 60 & $760(b)$ & & & \\
\hline & 500 & 60 & $2 \times 10^{-6}(a)$ & 550 & $40-50$ & 6 \\
\hline \multirow[t]{2}{*}{$\mathrm{V}$} & 480 & 60 & $760(b)$ & & & \\
\hline & 500 & 60 & $2 \times 10^{-6}$ (a) & 550 & $40-50$ & 12 \\
\hline \multirow[t]{2}{*}{ VI } & 480 & 60 & $760(\mathrm{~b})$ & & & \\
\hline & 500 & 60 & $2 \times 10^{-6}(a)$ & 550 & $40-50$ & 48 \\
\hline \multirow[t]{2}{*}{ VII } & 480 & 60 & $760(b)$ & & & \\
\hline & 500 & 60 & $2 \times 10^{-6}(a)$ & 550 & $40-50$ & 96 \\
\hline
\end{tabular}

(a) Vacuum annealing, (b) Hydrogen annealing 


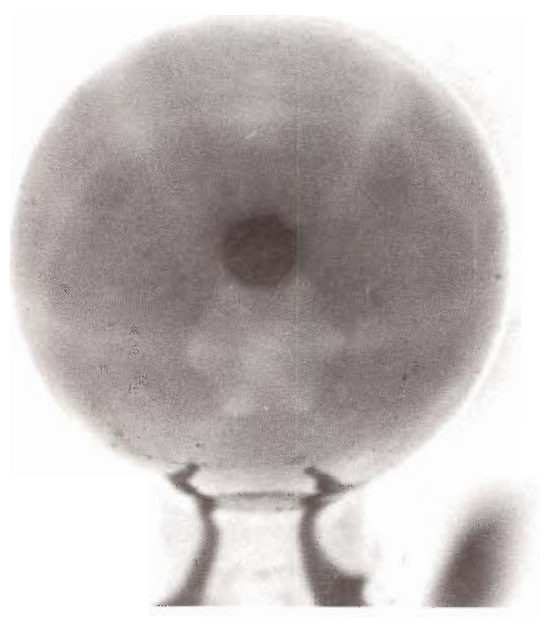

(a)

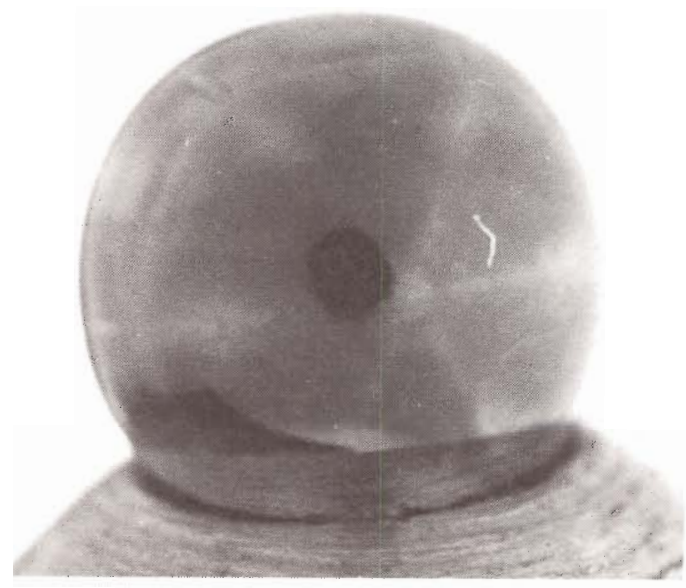

(c)

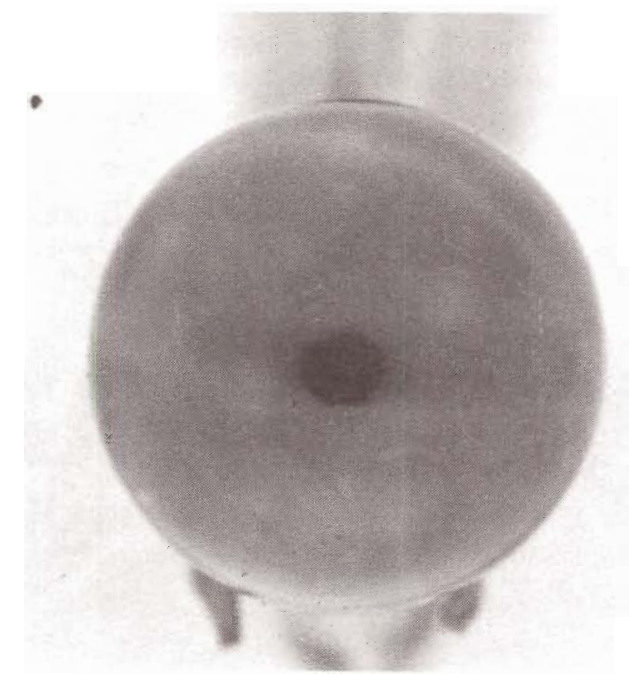

(b)

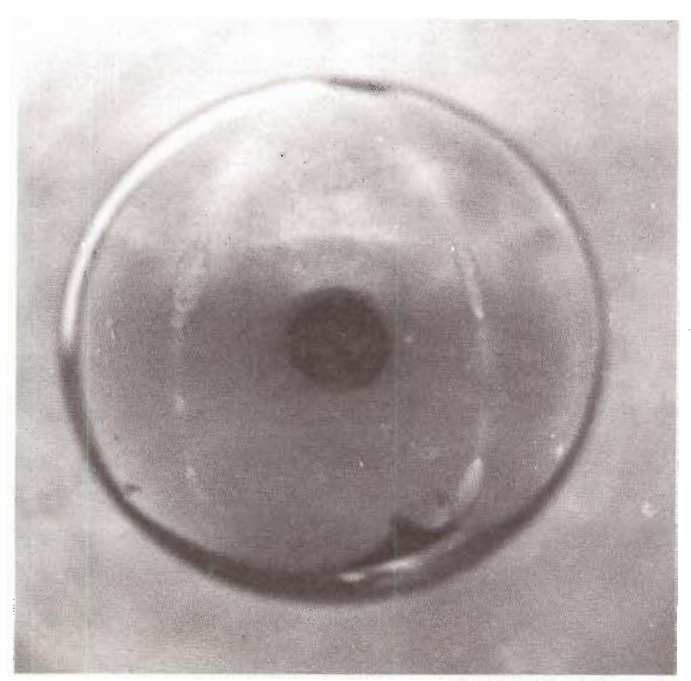

(d)

Figure 4. Pattern of Graphite Deposition on Ruthenium Single Crystal in $\mathrm{CO}$ at $550^{\circ} \mathrm{C}$
(a) and (b) 12 hours

(c) and (d) 48 hours 
Table 2. Results of RHEED on Specimens From Reactions IV and VI

\begin{tabular}{ccccc}
\hline \multicolumn{3}{c}{ Observed 'd' Spacings } & & \\
\hline Experiment IV & Experiment VI & Graphite 'd' Spacings (hk1) \\
\hline 3.35 & 3.345 & 3.35 & $(002)$ \\
2.01 & - & 2.13 & $(100)$ \\
- & 2.044 & 2.04 & $(101)$ \\
- & - & 1.801 & $(102)$ \\
1.546 & 1.752 & 1.675 & $(004)$ \\
1.206 & 1.227 & 1.541 & $(103)$ \\
- & 1.15 & 1.230 & $(110)$ \\
- & - & 1.154 & $(112)$ \\
- & - & 1.117 & $(006)$ \\
\hline
\end{tabular}

basal plane appeared to have only a light amount of graphite deposition. with a hexagonal shaped region centered about it. Farther from the $<0001>$ pole the graphite deposition became increasingly heavier. The dark graphitic deposits on the crystal were separated by narrow bands with lighter deposition. These bands were along the planes of $\langle 11 \overline{2} 0\rangle$ zones and along planes lying between $\langle 10 \overline{1} 1\rangle$ poles via the $\langle 11 \overline{2} 2\rangle$ poles. Figure 5 shows, on ruthenium stereographic projection, the area covered with relatively heavy amounts of graphite after reaction times of 12 and 48 hours. It is apparent from Figure 5 that the heavy deposition in the triangular region between $\langle 0001\rangle$ and $\langle 10 \overline{1} 1\rangle$ poles began near the respec- 


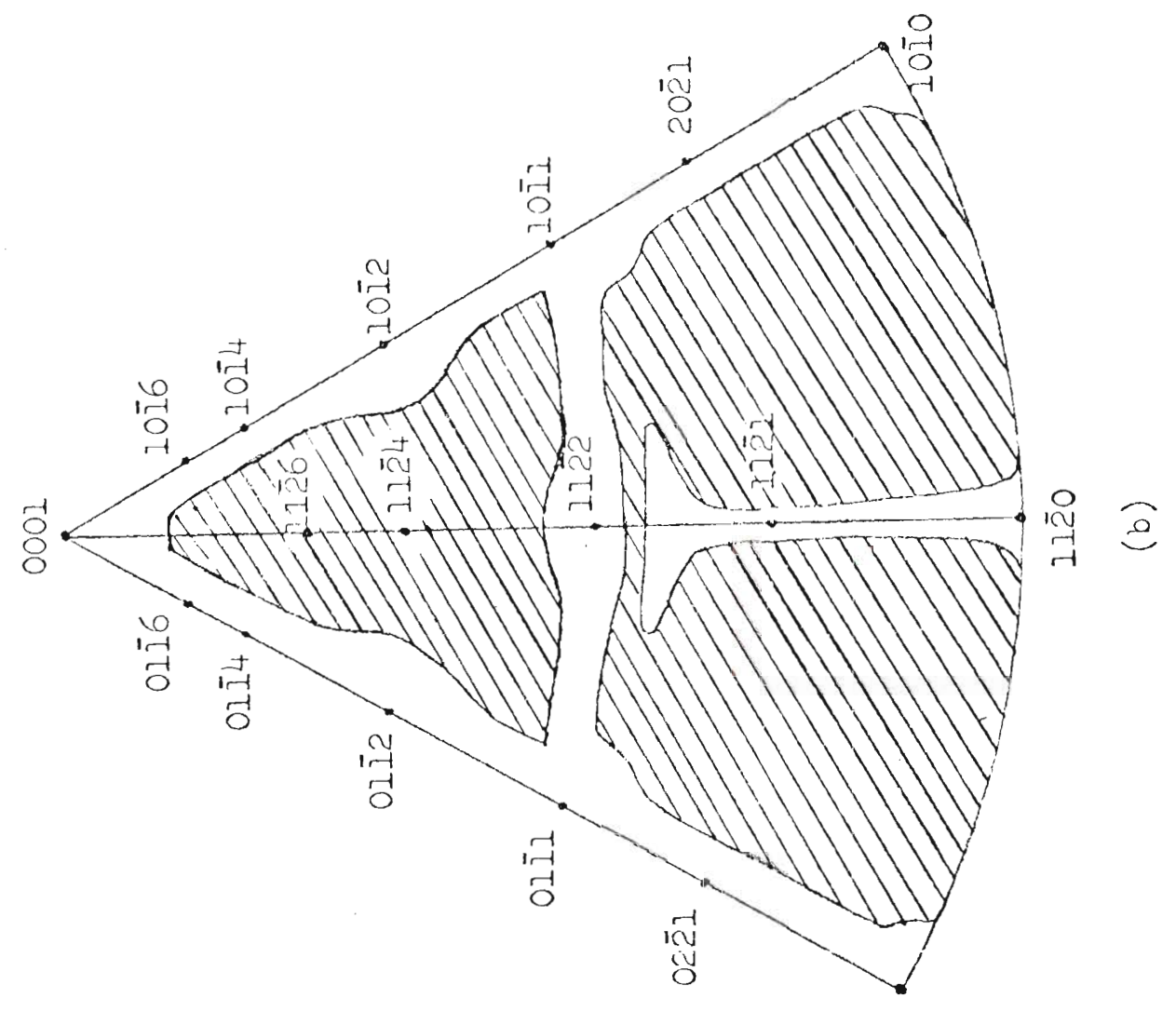

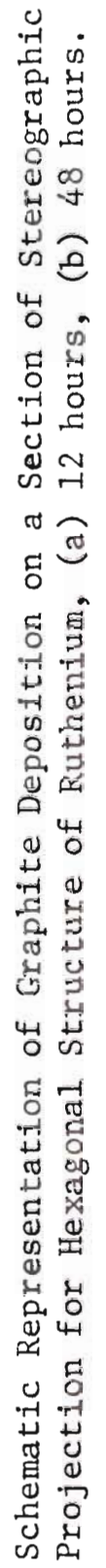

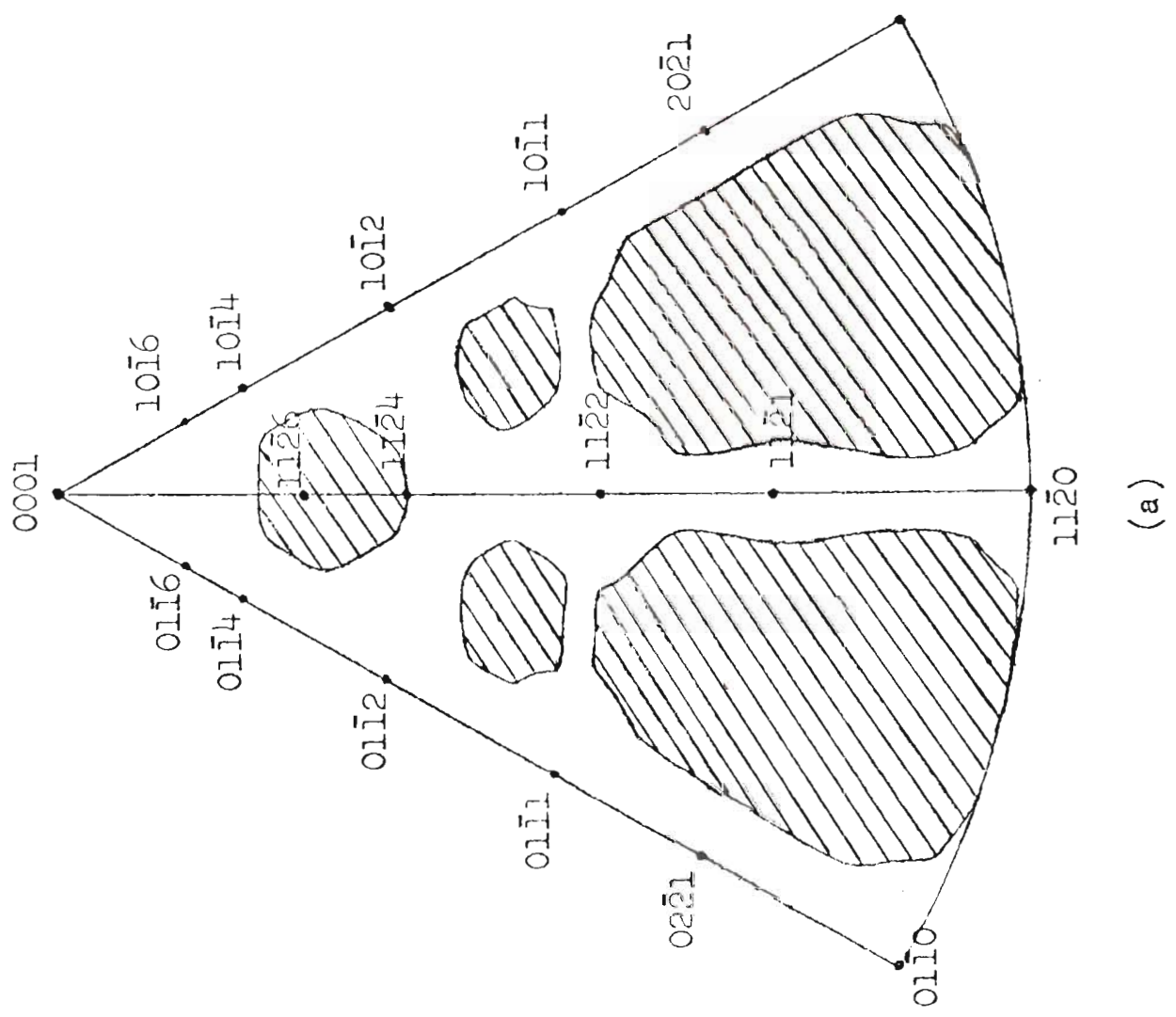

in 
tive low index poles (Figure 5a) and spread inward from there (Figure $5 b)$.

Two of the ruthenium crystals (Experiments V and VII) were examined after reaction by scanning electron microscopy, but the contrast was poor and the graphite deposits could not be resolved. The deposits, however, were readily observable with optical microscopy, and the results of these observations are given in the following paragraphs.

Very little detail could be seen in the heavy deposition regions, but the deposit morphology was discernible in the lighter deposition near low index poles. Much of the graphite appeared to be in the form of streamers, which varied in density, shape and size depending upon the ruthenium orientation. The streamers had heavier deposition at the 'head' followed by a trail of lighter deposition.

The streamers were formed in circles about $\langle 0001\rangle,\langle 10 \overline{10}\rangle$, and $<10 \overline{1} 1\rangle$ poles with their heads pointing to the respective low index poles. Figure 6a shows the graphite deposition around the <0001> pole and Figure $6 \mathrm{~b}$ the graphite streamers a short distance from this pole. It should be noted that the deposition was fairly heavy so that most of the streamers were overlapping, however, some isolated and reasonably distinct streamers are encircled, as examples, on the micrographs. (An additional difficulty encountered in obtaining clear pictures of the streamers was the highly curved surface on this $1 / 4$ inch diameter sphere). Moving farther from the <0001> poles, heads of the streamers became increasingly darker, the trail shorter and less distinct, until finally the graphite appeared as narrow bands. A similar arrangement of graphite streamers was observed around $\langle 10 \overline{11}\rangle$ and $\langle 10 \overline{10}\rangle$ poles, examples of 
which are shown in Figure $6 \mathrm{c}$ and $6 \mathrm{~d}$ respectively. The length of streamers about the $\langle 10 \overline{1} 1\rangle$ and $\langle 10 \overline{10}\rangle$ poles decreased more sharply along the direction towards the $\times 0001>$ poles than at right angles to that direction.

The graphite deposition on several high index regions is shown in Figure 7. The deposits near $\langle 20 \overline{2} 1\rangle,\langle 10 \overline{1} 2\rangle$, and $\langle 11 \overline{2} 2\rangle$ poles, as shown in Figure 7a through 7c, at first appeared to be streamers pointing to the respective high index poles. However, further examination showed that there was no circular pattern about the poles as in the case of deposits in the $\{0001\},\{10 \overline{10}\}$, or $\{10 \overline{1} 1\}$ regions. There was a smal1 amount of featureless graphite deposition on $\{11 \overline{2} 0\}$ regions, as shown in Figure $7 d$.

The graphite was very strongly adherent to the ruthenium surface and could not be removed by wiping with a cloth or by ultrasonic cleaning.

\section{B. Discussion}

The expectation that ruthenium would show a behavior similar to iron, cobalt, and nickel for the catalytic decomposition of carbon monoxide was confirmed; graphite was deposited on the surface of ruthenium when it was pre-reduced in hydrogen.

\section{Effect of Crysta1 Orientation on Activity}

The pattern of graphite decomposition showed that the activity for catalytic decomposition of carbon monoxide depended on the crystallographic orientation of the ruthenium surface.

The graphite first appeared on the ruthenium \{0001\} regions. This behavior was similar to that shown by nickel in several studies $(7,8$, 


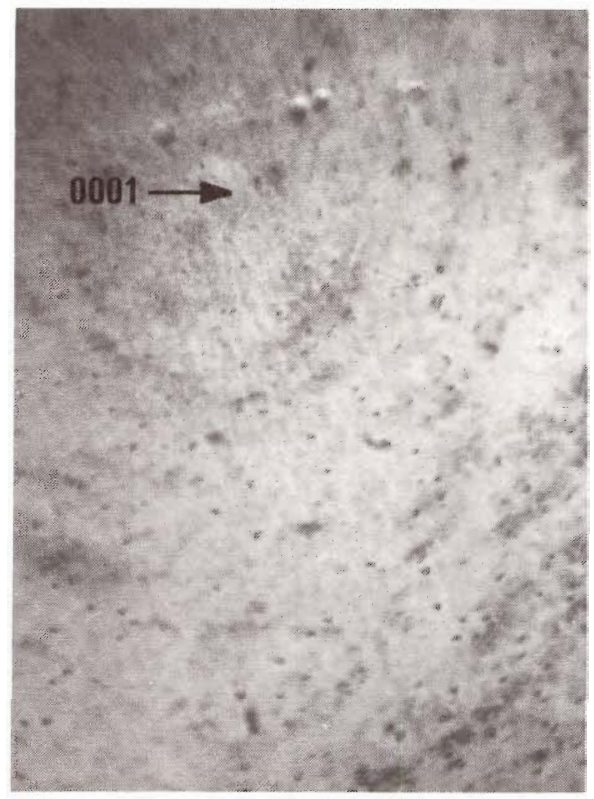

(a)

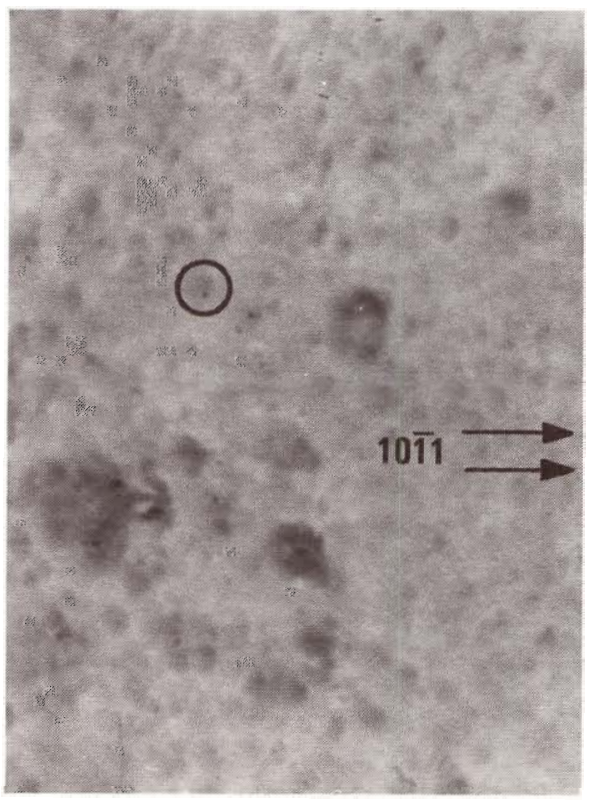

(c)

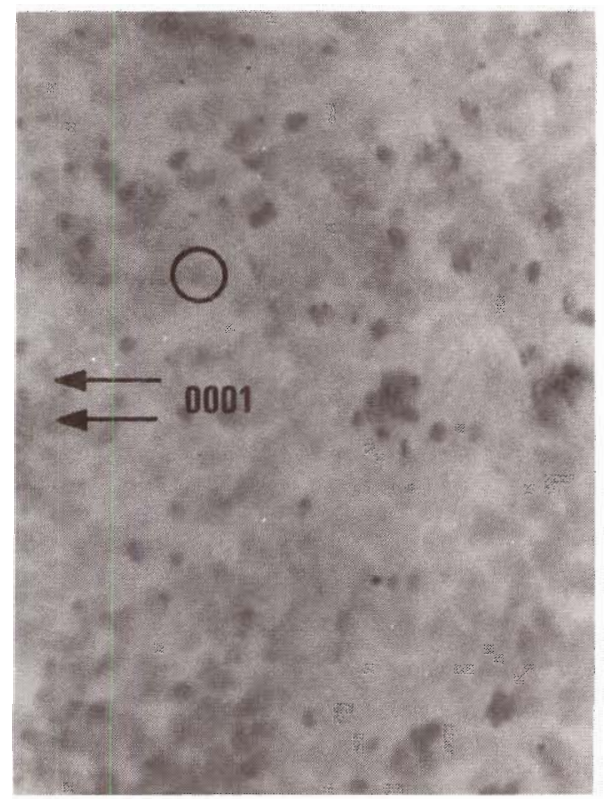

(b)

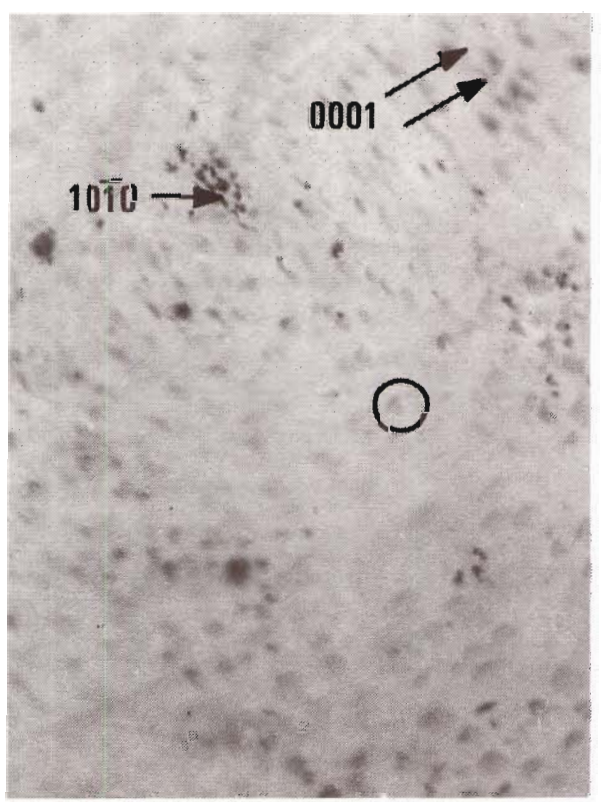

(d)

Figure 6. Optical Micrographs of Graphite Deposition on Low Index Regions

(a) (0001) region, X150

(c) (1011) region, $X 400$

(b) (0001) region, X400

(d) (1010) region, X200

Single arrow indicates position of the low index pole; Double arrow indicates relative position of a pole which is not in the field of view. 


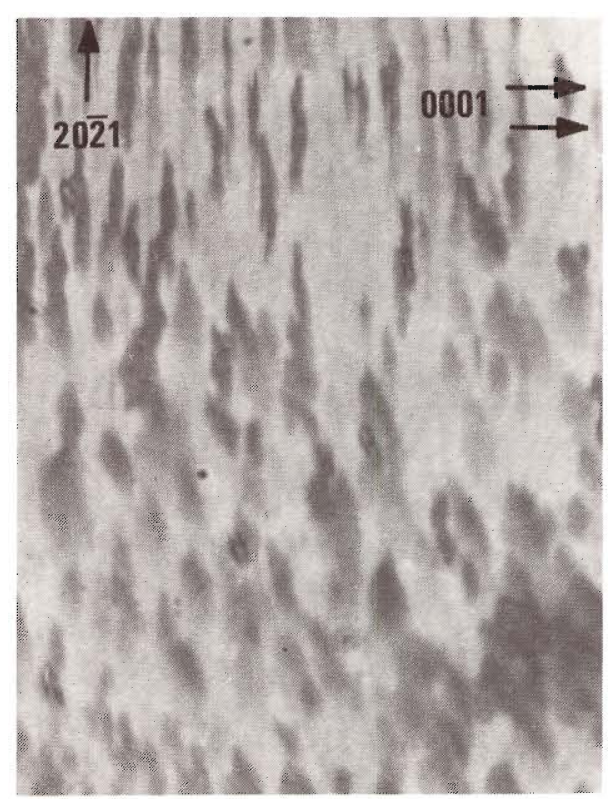

(a)

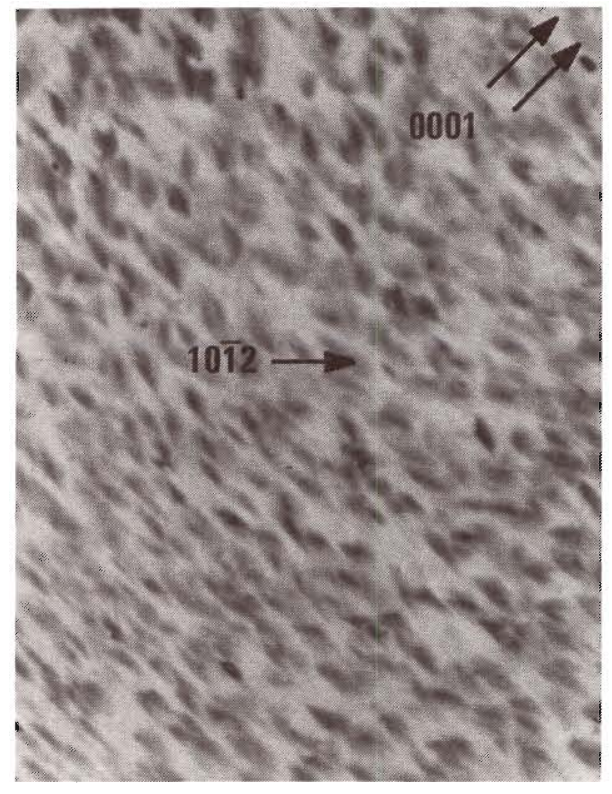

(c)

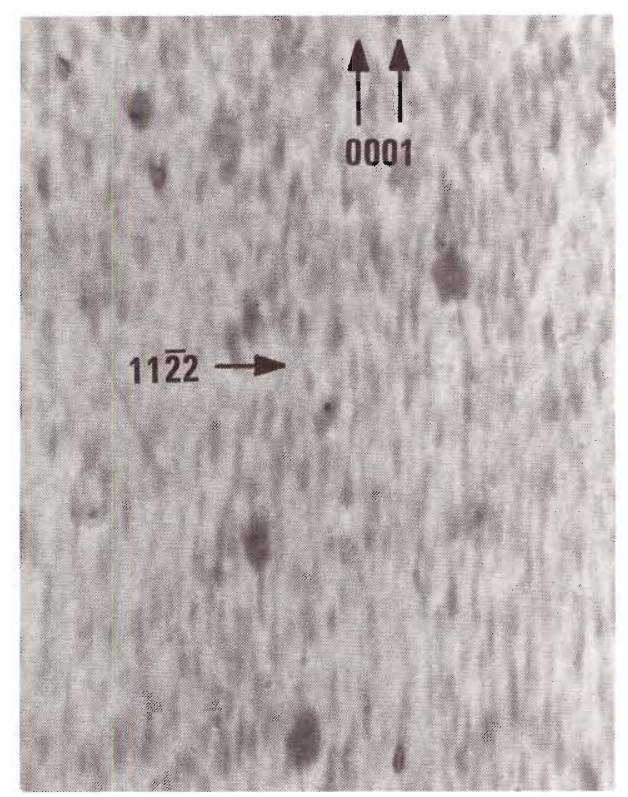

(b)

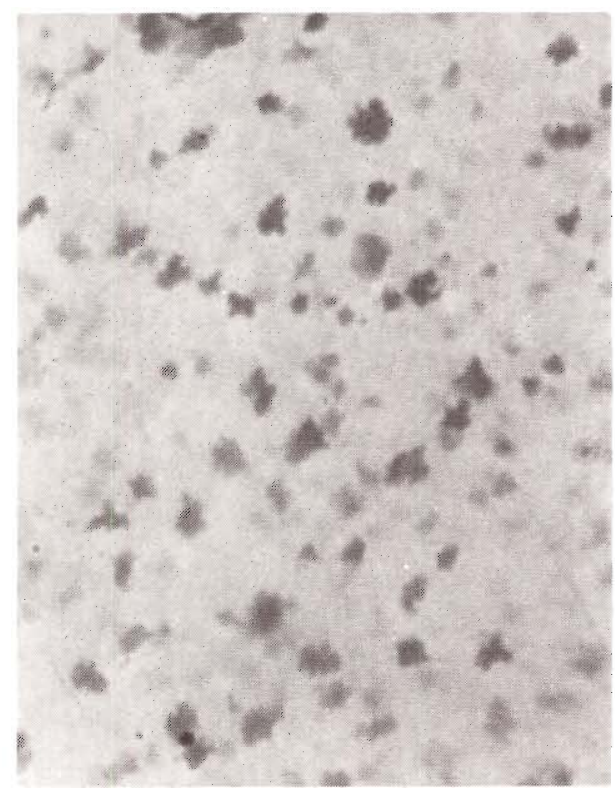

(d)

Figure 7. Optical Micrographs of Graphite Deposition on High Index Regions, X400

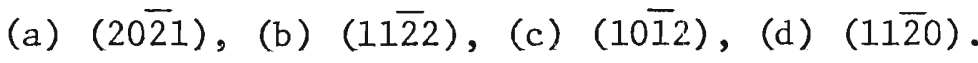


$10,11)$, where the close packed nickel $\{111\}$ regions were found to be the most active. For both cases, nickel (11I) and ruthenium (0001), by optical microscopy after moderate reaction time, very little graphite was found on the surface near the pole, but increasing amounts were found further from the pole. However, after Iong reaction times, the area in the immediate vicinity of the nickel (111) face had equally heavy graphite deposition in all directions; whereas in the case of ruthenium the planes of $\langle 11 \overline{2} 0\rangle$ zones had relatively $11 t$ tle graphite deposition. This resulted in the hexagonal pattern of graphite about the ruthenium (0001) face. Another major difference between nickel and ruthenium was that there were three active orientations on ruthenium $\{0001\},\{10 \overline{1} 0\}$, and $\{10 \overline{1} 1\}$, compared to only one on nicke1 $\{111\}$. The pattern of graphite deposition on ruthenium in this study is similar to that reported for hexagonal cobalt (10), the major difference being the reported high activity of cobalt $\{01 \overline{1} 3\}$ planes.

\section{Active Sites for CO Decomposition}

Active sites for catalytic reactions are the surface features on the catalyst where the reaction occurs. In the case of carbon monoxide decomposition on nickel, Grenga (4) found that graphite nucleated at certain steps between terraces of low index planes. She proposed that the observed nucleation sites were at or very near the active sites for the catalytic reaction. Both theoretical and experimental evidence to support this were cited. It was also pointed out that the activity of steps or other surface features would be a function of the catalytic reaction and catalyst. In the present studies on bulk ruthenium, the reaction conditions were similar to those used in the above studies. It 
is therefore expected that the morphology of the graphite deposits can be related to the active sites for this catalytic reaction on ruthenium. As reported in the section on results, the graphite was initially deposited in a circular pattern about the three major types of low index poles, $\langle 0001\rangle,\langle 10 \overline{10}\rangle$, and $\langle 10 \overline{1} 1\rangle$. The density of deposits or streamers increased with distance from each pole. These observations are consistent with nucleation at steps between terraces of the low index planes as explained below.

For a spherically shaped single crystal, a low index plane is located directly at the pole with the same indices. Further from the pole there are terraces of this plane separated by steps between the terraces. Since the crystal is spherical, the steps will form a circular pattern centered about the pole, and the distance between the successive steps will decrease as the distance from the pole increases.

If steps between terraces of low index planes are active sites, and if graphite from the carbon monoxide decomposition nucleates at these active sites, then the graphite deposition should be centered about the low Index pole and the density of deposits should increase with distance from the pole. It should be noted, however, that high index planes which consist entirely of such steps were found to be inactive on nickel. For ruthenium, while the graphite eventually covered many such high index planes (for example $\{11 \overline{2} 4\}$ ), it was evident that deposition began on low index regions and grew outwards from these regions to eventually cover the high index planes. The observed morphology of graphite in these studies therefore indicates that the active sites for the catalytic decomposition of carbon monoxide on ruthenium are also at the steps between 
terraces of low index planes.

There were indications that not all surface steps on a given crystal region were equally active, similar observation to that made on nickel (4). This resulted in the hexagonal pattern about the <0001> poles as well as the regions of lighter deposition centered about the $\langle 10 \overline{10}\rangle$ and $\langle 10 \overline{1} 1\rangle$ poles. 
CHAPTER V

CONCLUSIONS AND RECOMMENDATIONS

\section{A. Conclusions}

From this research the following conclusions were drawn;

1. Carbon monoxide catalytically decomposes to deposit graphite on the surface of ruthenium at 500 to $550^{\circ} \mathrm{C}$.

2. The activity of ruthenium for the catalytic decomposition of carbon monoxide is primarily influenced by crystal orientation.

3. The $\{0001\},\{10 \overline{1} 1\}$ and $\{10 \overline{10}\}$ regions are the most active for this reaction, and certain steps on these regions are the active sites.

4. Steps on the 1ow index regions 1ying along $\langle 11 \overline{2} 0\rangle$ zones appeared to be relatively inactive as were other planes of this zone.

5. The $\{11 \overline{2} 0\}$ regions were relatively inactive for the Co decomposition.

\section{B. Recommendations}

The following recommendations can be made for future work that would supplement the results of the present work and contribute to the understanding of the heterogeneous catalysis:

1. Kinetics studies should be made for the catalytic decomposition of carbon monoxide on ruthenium.

2. Flat surfaces, corresponding to active low index regions, should be cut on the sphere to provide a larger surface area of these regions. After reaction with carbon monoxide, extraction replicas should 
be examined with transmission electron microscopy to give more detailed information about the graphite morphology and any epitaxial relations between graphite and ruthenium.

3. The catalytic decomposition of other carbonaceous gases like methane and ethylene on ruthenium should be investigated to determine whether the active sites are similar to those for carbon monoxide decomposition.

4. Chemisorption studies of carbon monoxide on ruthenium, currently being done in this laboratory, should be compared with the results of the present work, to ascertain any relation between chemisorption and active sites. 
LITERATURE CITED

1. F. Olmer, J. Phys. Chem. 46 (19.42) 405.

2. A. R. McKinney, J. Phys. Chem. 47 (1943) 152.

3. H. Leidheiser and A. T. Gwathmey, J. Am. Chem. Soc. 70 (1948) 1200, 1206.

4. H. E. Grenga and K. R. Lawless, J. App1. Phys. $43 \underline{4}$ (1972) 1508.

5. H. E. Grenga, Ph. D. Dissertation, University of Virginia (1967).

6. M. Hansen, 'Constitution of Binary Alloys', McGraw Hill Book Co. (1958) 378.

7. A. T. Gwathmey and R. E. Conningham, Adv. in Catalysis, 10 (1958) 57.

8. A. T. Gwathmey and R. E. Conningham, Adv. in Catalysis, 9 (1957) 25 .

9. A. T. Gwathmey, Record of Chemica1 Progress, 14 (1953) 117.

10. V. J. Kehrer, Jr. and H. Leidheiser, Jr., J. Phys. Chem. 58 (1954) 550 .

11. E. Cox, et a1., Actes Du Deuxieme Congres International De Catalyse, Paris, (1960) 1605.

12. James Titus Ratliff, Ph. D. Dissertation, Georgia Institute of Technology, (1968).

13. P. V. Shchigolev, 'Electrolytic and Chemical Polishing of Metals', Freund Publishing House, Israel, (1970).

14. P. A. Jaquet, Met. Rev. 1 (1956) 157.

15. G. V. Samsonov, 'The Oxide Handbook', Plenum, (1973).

16. W. J. Tegart, 'Electrolytic and Chemical Polishing of Metals in Research and Industry', Pergamon Press, (1959).

17. S. B. Chakrabortty, M. S. Thesis, Georgia Tech. (1971).

18. A. J. Melmed and R. Klien, J. Less Common Metals, 10 (1966) 225, 368. 
19. S. B. Chakrabortty and H. E. Grenga, J. Applied Phys. 44 (1973) 500 .

\section{Other References}

1. L. C. Isett and J. M. Blakely, J. Vac. Sci. Technol. 12 (1957) 237.

2. N. N. Kavtaradze and N. P. Sokolova, Russ. J. of Phys. Chem. 41 (1967) 225.

3. A. S. T. M. Data File for X-ray Diffraction.

4. J. T. Grant and T. W. Haas, Surface Sci. 21 (1970).

5. R. F. Hochman, 'Metal Deterioration in High Temperature Carbonaceous Environment', Annual Report No. 1, Georgia Tech. (1965).

6. A. R. Cox, M. S. Thesis, Georgia Tech. (1962).

7. R. V. Westerman, Ph. D. Dissertation, Georgia Tech. (1967).

8. R. J. Kokes, in 'Catalysis-Progress in Research' Edited by Fred Basolo and R. L. Burwell, Jr. Plenum (1973) 75.

9. Charles Kimba11, Ibid. p. 85.

10. M. Kobayashi and T. Shirasaki, J. Catalysis 28 (1973) 289. 